\title{
Divergence of renewable energy invention efforts in Europe: an econometric analysis based on patent counts
}

\author{
Jonas Grafström ${ }^{1}$
}

Received: 17 March 2017 / Accepted: 7 April 2018 / Published online: 19 April 2018 (C) The Author(s) 2018

\begin{abstract}
The objective of this paper is to investigate the presence of convergence (or divergence) of invention efforts per capita in the renewable energy field across European Union (EU) countries. Divergence may imply a risk of a lower level of goal fulfilment regarding the share of renewable energy in the EU energy mix. This is due to free-rider issues and sub-optimal investment levels, in turn making it more expensive and cumbersome to expand renewable energy production. Convergence suggests a possible faster renewable energy goal achievement. The econometric analysis is based on patent application counts per capita for 13 EU Member States over the time period 1990-2012. The methods used draw on the economic convergence literature. First, we rely on a panel data set to test for conditional $\beta$-convergence. Moreover, a distributional dynamics approach is employed to test for $\sigma$ - and $\gamma$-convergence, and analyse the intra-distributional dynamics. The results indicate conditional $\beta$ - and $\sigma$-divergence in renewable energy invention capabilities across the 13 countries, thus suggesting that some EU countries tend to free-ride on the development efforts of other Member States.
\end{abstract}

Keywords Convergence $\cdot$ Divergence $\cdot$ Renewable energy development $\cdot$ Patent counts $\cdot$ EU

JEL Classification $\mathrm{O} 30 \cdot \mathrm{O} 40 \cdot \mathrm{O} 44 \cdot \mathrm{P} 18$

An earlier version of this paper was presented at the 39th International Conference of the International Association for Energy Economics, Bergen, Norway 19-22 June, 2016.

Jonas Grafström

jonas.grafstrom@1tu.se

1 Economics Unit, Luleå University of Technology, 97187 Luleå, Sweden 


\section{Introduction}

The Renewable Energy Directive (2009/28/EC) of the European Union (EU) establishes a binding target to ensure at least $20 \%$ share of energy consumption from renewable sources by the year 2020. To achieve this overall target, the EU Member States have committed themselves to national renewables' targets (European Commission 2015a). In October 2014, the EU further enhanced the scope of its climate and energy targets for both 2020 and 2030; its 2030 policy framework sets a minimum target of $27 \%$ in respect to renewable energy sources as well as energy savings by 2030 (European Commission 2014).

At EU level, renewable energy's share of the gross final energy consumption has grown over time, e.g., from about 9\% in 2005 to roughly 16\% in 2014 (European Commission 2015b). Moreover, on the technological side, the development is rapid. The number of renewable energy patent applications filed for at the European Patent Office (EPO) has increased annually by more than $20 \%$ in the recent years, while the average increase for other technologies only was around 6\% (EPO 2016). However, the renewable energy outcomes in individual EU Member States are heterogeneous, with substantial capacity and patenting increase in some countries and far more modest developments in others (IEA 2014a; Strömberg 2013). ${ }^{1}$ These diverging pathways may give rise to concerns about an unfair burden-sharing among EU countries. Such concerns are likely to be a particularly thorny issue, if they are accompanied by diverging efforts to develop the associated new technology, e.g., through private as well as public research and development (R\&D) activities.

The objective of this paper, therefore, is to investigate whether or not per capita renewable energy patent applications in the renewable energy field have converged (or diverged) across EU Member States. The econometric analyses rely on data on per capita patent applications in 13 EU countries during 1990-2012. In this empirical context, convergence (Latin convergere-meet, unite) would imply that countries with lower initial per capita patent application production levels would experience relatively higher growth rates in patenting activity than other countries, thereby eventually closing in on the countries that have been forerunners in this field. Since the knowledge generated in one EU country is largely a public good from which several countries can benefit at the same time, one could argue that convergence among the countries in terms of patenting outcomes is not important. However, there are both political and economic arguments for why such convergence may be desirable.

The political motives relate to the importance of maintaining public acceptance for the financial burdens that consumers in the EU carry when the energy system is transformed. This transformation largely derives from key EU directives, and it requires the participation of all Member States. For instance, evaluations of the prospects for wind power expansion have stressed the importance of public acceptance in

\footnotetext{
1 Several EU countries are expected to accomplish their policy goals. However, EU Member States such as France, Luxembourg, Malta, the Netherlands and the United Kingdom face a need to assess whether the domestic efforts undertaken are sufficient for meeting their respective renewable energy objectives (European Commission 2015b).
} 
combination with political stability and legal aspects (e.g., Söderholm et al. 2007). If some countries perceive that other countries are free-riding on their development efforts, and that they, therefore, have to carry a disproportional part of such efforts, the overall EU energy and climate policy targets will potentially be more difficult and costly to achieve (Corradini et al. 2015). ${ }^{2}$

The economic arguments for convergence in patenting outcomes are multifold. In order for a country to respond to changes in external constraints, it needs to be equipped with adequate scientific and technological knowledge, i.e., a country needs so-called absorptive capacity. Here absorptive capacity concerns countries' abilities to absorb knowledge developed abroad (Antonelli 2008; Antonelli and Quatraro 2010; Costantini and Crespi 2008a, b; Dosi et al. 1988; Fagerberg et al. 2005; Rennings, 2000). Hence, international technology flows crucially depend on the destination country's ability to comprehend - and make use of - external knowledge (Mancusi 2008). The ability to generate value from the presence of technological spillovers, such as knowledge on how to adopt, adapt and implement new renewable energy technology, will in turn be a function of the country's experience in relevant R\&D (Cohen and Levinthal 1989). The importance of absorptive capacity may, therefore, support a scenario of convergence of renewable energy development activities across countries.

Following Kerstens and Managi (2012), the issue of convergence/divergence has important implications for growth theory where there is a possibility that there is non-convexity in the production function. In production analysis convexity is typically assumed. However, several empirical studies point at a possibility of industries where convexity does not hold (e.g., Tone and Sahoo 2003). Kerstens and Managi (2012) found that non-convexity may exist in the petroleum field and hence possibly in other fields (such as electricity generation), hence we should not take the convexity for granted. Hence, if the convexity in the production possibility set cannot be taken for granted, then there are reasons to expect the possibility of divergence instead of convergence.

Bosetti et al. (2008) found that the strongest technological free-riding effects with regard to renewable energy occur among high-income countries. These countries are more able than low-income countries to expose themselves to the international exchange of new ideas and, thus, gain greater benefits in terms of potential investment savings. Countries that are less developed economically and technologically often face barriers that prevent them from absorbing international knowledge spillovers. Furthermore, the speed of innovation in the renewable energy sector will be higher, if more countries are engaged in R\&D and invention activities (Costantini and Crespi 2013; Costantini et al. 2015). Given the urgency of addressing the accumulation of greenhouse gases in the atmosphere, the relatively rapid development of low-cost, carbon-free technologies will be of great value.

The research question, namely whether or not renewable energy patent applications per capita have converged or diverged, is addressed empirically by performing

\footnotetext{
${ }^{2}$ For a theoretical foundation on why national governments could choose to reduce $\mathrm{R} \& \mathrm{D}$ spending in an open economy in the presence of international knowledge spillover, see e.g. Park (1998).
} 
several types of convergence tests. Conditional $\beta$-convergence is tested first, i.e., convergence after the differences in the steady states across countries has been controlled for. This type of conditional convergence is tested by regressing average growth rates on the initial level (while controlling for other exogenous factors). Thereafter, a distributional dynamics approach is employed to test for so-called $\sigma$-convergence (the narrowing of the distribution), i.e., to show whether the dispersion of per capita renewable energy patent applications across the EU countries tends to decline over time. In the next step, we analyse how the distribution changes over time. Finally, the $\gamma$-convergence (i.e., movement within the distribution) test results are presented, revealing the changes in an index of rank concordance.

The main contribution of this paper is its novelty-in terms of data, time period and estimation approach-with respect of investigating convergence in an important field of sustainable economic growth, i.e., the development of renewable energy technology. This issue has so far not been investigated in the form proposed.

The remainder of the paper is organised as follows. In Sect. 2, previous environmental convergence research and technological change literature are reviewed. Section 3 presents the methods applied. Section 4 presents the data used, and discusses the use of patent applications as a proxy for invention activities. Section 5 synthesises the empirical findings from the various convergence models and discusses the results. The paper ends with Sect. 6, which summarises the key conclusions and outlines suggestions for future research.

\section{Previous convergence research and the case for (and against) convergence of invention outcomes}

In economics, the concept of convergence has its origins in the classic Solow growth model dating back to 1956 . The initial historical empirical tests of the convergence hypothesis focused on real gross domestic product (GDP) per capita, and the presence of so-called $\beta$-convergence. The reason we should expect convergence of per capita GDP, according to the historical test results and economic theory, is that there are decreasing returns to capital. One consequence of decreasing returns to capital is that poorer countries can be predicted to experience higher growth rates than the richer countries (Barro 1991a, b). Capital will flow to countries where the return to investment is larger, and this is usually where wages are low, at least if the country's institutions are favourable for economic development (Maurseth, 2001). ${ }^{3}$ In this way, the initially poorer countries will tend to catch-up with the richer ones, and we have $\beta$-convergence.

However, without a minimum level of technological capability (know-how), it is essentially impossible for a firm or a country to achieve deeper capabilities and

\footnotetext{
3 Recent endogenous growth theorists (e.g., Barro and Sala-i-Martin 1992; Islam 2003; Lucas 1988; Romer 1986) have criticised the convergence hypothesis by pointing out several instances where per capita income has failed to equalise across rich and poor countries over time.
} 
improve existing technologies; hence, there are incentives to allocate some resources to domestic R\&D (e.g., Cohen and Levinthal 1989; Hussler 2004; Mancusi 2008).

Several researchers have emphasised the decisive role that technology plays in economic convergence in the long run. For example, in a study by Žižmond and Novak (2007) on technological convergence (defined in terms of gross fixed capital formation) between the 15 initial and the 8 later EU Member States, the authors found significant technological convergence. In a regional study over a set of European countries, Martin et al. (2005) revealed that, as the distribution of patents and public R\&D converged, income per capita converged too. Jungmittag (2004) showed that, if technologies varied across countries, convergence of per capita incomes and labour productivities would only occur in the presence of a converging development of national innovation capabilities. In addition, Fagerberg et al. (2005) found that there had been a convergence of income and productivity levels in Europe after the Second World War, but that this convergence process slowed down and gradually ended during the 1980s.

The limited body of past research that addresses technological convergence has thus far concentrated on aggregates, such as all patents, or productivity in general. However, subfields of technology, such as developments in renewable energy, have not been investigated to date. ${ }^{4}$ Within the realm of technological convergence, two previous studies that have explored convergence in respect of inventive capabilities in Europe have some relevance for the current paper. Archibugi and Filippetti (2011) used a $\beta$-convergence panel test to investigate how the global financial crisis of 2008 affected R\&D investment convergence in the EU, and found divergence in their sample of Member States. Jungmittag (2006) investigated the convergence of inventive capabilities using general patent data during the period 1963-1998. The current paper differs from these two studies (besides focusing on a narrower technological field) in that: (a) it applies multiple econometric approaches, it uses more recent data; and (b) it provides a more in-depth discussion on the potential underlying causes of both convergence and divergence.

Overall, there is a case to be made for both convergence and divergence in terms of invention efforts and outcomes. Arguments for finding convergence are: (a) from a pure mathematical perspective, it can be assumed that laggard countries can grow faster (in percentage terms) than the more technologically developed countries (since growing from something small will give large growth rates). This relatively fast growth will lead to a catch-up with the more developed countries, at least in the long run (Keefer and Knack 1997); (b) disruptive inventions can render a country's lead less valuable if they are looked into as a stagnant technology; (c) public policy can push countries to reach certain goals, disregarding costs; and (d) the emergence of better opportunities to make use of knowledge spillovers from abroad may arise due to intensifying cross-country interactions; even though the laggard

\footnotetext{
${ }^{4}$ However, the economic literature does address convergence in environmental performance, e.g., of per capita carbon dioxide emissions (Aldy 2006; Brock and Taylor 2010; Nguyen-Van 2005; Romero-Ávila 2008; Strazicich and List 2003). See Pettersson et al. (2014) for a review of the carbon convergence literature.
} 
countries might not generate breakthrough patents, there could be room for incremental improvements.

Divergence may occur because the knowledge generated is a public good, ${ }^{5}$ which implies that some countries may free-ride on other countries' development efforts. Furthermore, speaking against converging per capita renewable energy patent levels is, for instance, technological cluster theory. This is in turn in line with theories of economic geography, which suggest that clustering occurs in the same industry, because proximity generates positive externalities or "agglomeration effects" (Head et al. 1995; Rosenthal and Strange 2001). In the case of technological research, this theory implies there will be increasing returns on investments in areas where other research activities already exist (e.g., Porter 2000). In other words, inventive firms in a particular industry will establish themselves geographically in countries and regions where other inventive firms in the same industry can be found. Researchers will, in turn, leave laggard countries and instead take up employment in countries where there are larger economic returns on new ideas. The most commonly used example of a cluster in an industry is Silicon Valley; here high-tech firms have established despite production costs being significantly higher than, for example, in rural Idaho. Positive spillovers across complementary R\&D activities provide stimulus for agglomeration; thus, the growth rate of a technology within a country may increase according to the 'strength' (i.e., relative presence) of related R\&D activities (Delgado et al. 2014).

In sum, the above indicates rationales for the presence of both convergence and divergence in terms of renewable energy development activities across countries. The notion that the new knowledge generated has important public good characteristics in combination with technological cluster theory support the divergence hypothesis. In contrast, the importance of absorptive capacity, and the subsequent need to promote domestic R\&D to make use of the knowledge develop abroad, tends to support the convergence hypothesis (or at least a lower speed of divergence).

\section{Methodological approaches}

To study the convergence/divergence issue, four approaches are applied. They are meant to be complimentary to each other. Neoclassical convergence $(\beta)$, Sigmaconvergence $(\sigma)$, distributional convergence and $\gamma$-convergence is used. The $\beta$-convergence test is supplemented with the $\sigma$-convergence test. The advantage of using the $\sigma$-measure is twofold. The first advantage is that it is an unbiased measure of $\beta$-convergence. By looking at the process over time, one can see if it is possible to detect significant periods during which some sort of break in the development

\footnotetext{
${ }^{5}$ Knowledge is typically a public good. A pure public good has defining characteristics; the consumption of it by one individual does not actually or potentially reduce the amount available to be consumed by another individual, and no one can be excluded from consumption. However, not all knowledge constitutes pure public goods. If renewable energy technologies are improved but the new knowledge cannot be appropriated at no (or a low) cost, then the public good is an impure public good.
} 
occurred. Second, the measure of $\sigma$-convergence allows us to track the evolution of the convergence process over time. Following the $\sigma$-convergence over time enables the identification of visible peaks in the distribution, e.g., shocks that have affected the development process around a specific period.

There are weaknesses with the $\sigma$-convergence test. Some researchers (e.g., Desdoigts 1999; Quah 1997) have suggested that interpreting measures of dispersion, as $\sigma$-convergence may not be straightforward if the distributions are not uni-modal. This is because outliers can be an important driver of $\sigma$-convergence (e.g., if one or more countries are developing rapidly, this can be driving what appears as overall divergence). Hence, distributional convergence model and $\gamma$-convergence is used.

There are more approaches to convergence (extended distributional dynamics and stochastic convergence) in the literature and some words regarding the exclusion of those are warranted. In the convergence literature, there is an increased use of distributional dynamics methodology to reveal things that the $\beta$ - and $\sigma$-plot cannot reveal such as twin peaks, polarization and stratification. To achieve this, different couture plots can be used based on, for example, a bivariate kernel function. However, following Jaunky (2013) a large sample size is preferably required for a reliable estimation of multivariate kernel densities, since "the curse of dimensionality" affects the possibility to assess the result. The sample size, therefore, tends to determine the principle limits of the distribution dynamics method (Ahamada and Flachaire 2010), since it can be quite challenging to interpret distributions with dimensions higher than two especially if observations are relatively few. In the $N=13$ case, as in this paper, Boyle and McCarthy (1997) seemed appropriate to adhere to where the kernel approach is indeed "... not parsimonious of estimation effort". Boyle and McCarthy (1997) had a solution where they indeed argued about the lack of merit of generality of the $\sigma$-convergence measure in testing for $\beta$-convergence and put forward an alternative measure known as $\gamma$-convergence which is used in this paper.

A weakness with only using four methods for the data analysis is that a more in-depth investigation of the development such as issues of mobility, stratification and polarization is not covered with the chosen methods (see e.g., Quah 1993a, b; 1996a, b, 1997; Durlauf et al. 2005). However, the four chosen methods are sufficient to answer the research question this paper sets out to answer which limits itself to investigate the general direction of the development.

\subsection{The neoclassical convergence model}

For our purposes, $\beta$-convergence occurs when the per capita renewable energy patent applications of laggard countries, i.e., those with lower initial levels of renewable energy patent applications per capita, grow faster than the more patent-intensive countries. The conditional $\beta$-convergence model in turn assumes the presence of different steady-state levels for the various countries. ${ }^{6}$

\footnotetext{
6 There are two concepts of $\beta$-convergence, absolute and conditional. In this paper, conditional convergence is investigated. In our case, $\beta$-convergence is absolute if countries with a low level of patent production and those with a high level have the same steady-state or long run level of produced patents per capita.
} 
Conditional $\beta$-convergence can be examined by adding a set of exogenous variables to Eq. (1), where differences in the steady states across countries are controlled for (Barro and Sala-i-Martin 1991, 1992; Barro 2015). Specifically, in a panel data setting conditional $\beta$-convergence can be tested through a transformed Barro growth equation. ${ }^{7}$ We thus have:

$$
\Delta y_{i t}=\alpha+\beta_{c} \ln \left(y_{i t-1}\right)+\beta X_{i t}+\delta_{i}+\eta_{t}+\varepsilon_{i t},
$$

where $\Delta y_{i t}=\ln \left(y_{i t} / y_{i, t-\tau}\right)$ is the growth rate in the number of per capita renewable energy patents between time period $t-\tau$ and $t$, and; $y_{i t-1}$ is the lagged dependent variable. Furthermore, $\delta_{t}$ addresses country-specific fixed effects, $\eta_{t}$ represents period-specific effects, and $\varepsilon_{i t}$, is the error term. A vector $\beta X_{i t}$ consisting of the additional explanatory variables, including human capital, is also added to the equation (see further below).

The estimation of Eq. (1) is straightforward. An estimate of $\beta_{c}<0$ implies $\beta$-convergence. ${ }^{8}$ The baseline specification of the conditional $\beta$-convergence model is presented in Eq. (2):

$$
\Delta y_{i t}=\alpha+\beta_{c} y_{i t-1}+\beta_{1} K_{i t}+\beta_{2} R E S_{i t-2}+\beta_{3} O P_{i t-2}+\beta_{4} E I_{i t-2}+\delta_{i}+\eta_{t}+\varepsilon_{i t} .
$$

$K_{i t}$ is an R\&D-based knowledge stock taking into account the accumulated public expenditures to support renewable energy $\mathrm{R} \& \mathrm{D}$ in the respective countries; $R E S_{i t}$ is a variable measuring the number of researchers per 1000 in the labour force; $O P_{i t}$ is the oil price; and $E I_{i t}$ represents energy import dependence (all variable definitions and sources are presented in detail in Sect. 4). The non-stock control variables are lagged 2 years. For example, public R\&D expenditures taking place in period $t$ are assumed to lead to a patent application no earlier than in period $t+x(x=2)$ (Nicolli et al. 2012).

Following Brännlund et al. (2015), the specification in Eq. (2) can be developed further by allowing $\beta_{c}$ to vary across countries. Hence, we allow the speed of convergence to vary. We introduce interaction effects to allow for these different convergence speeds, and specify the following alternative model:

$$
\begin{aligned}
\Delta y_{i t}= & \alpha+\beta_{c} y_{i t-1}+\beta_{1} K_{i t}+\beta_{2} \mathrm{RES}_{i t-2}+\beta_{3} \mathrm{OP}_{i t-2}+\beta_{4} \mathrm{EI}_{i t} \\
& +\beta_{5} y_{i t-1} \mathrm{IEI}_{i t}+\beta_{6} y_{i t-1} \mathrm{IKS}_{i t}+\delta_{i}+\eta_{t}+\varepsilon_{i t} .
\end{aligned}
$$

In Eq. (3), the parameters $\mathrm{IET}_{i t}$ and $\mathrm{IKS}_{i t}$ represents the variables that are interacting - in this paper, Interaction-Energy import dependence and InteractionKnowledge stock. Both these variables are expected to affect the growth path of renewable energy patent applications. The hypothesis regarding the Interaction-Energy import dependence variable is that countries that are energy import

\footnotetext{
7 The variables chosen for the Barro growth equation has its foundation in the knowledge production framework (see e.g., Griliches 1979; Nelson 1987; Jaffe 1986).

8 The speed of convergence and the half-life for the conditional $\beta$-convergence models can also be calculated. Following Islam (1995), we have $\beta_{c}=\exp ^{-\lambda \tau}$, where $\lambda$ measures the speed at which the level of per capita patent applications approaches its own steady-state level.
} 
dependent are dependent on externally supplied fossil fuels: they are, therefore, incentivised to consider energy security and develop domestic renewable energy production. In general, a higher knowledge stock should have a positive effect on a countries patent production, however, according to Acemoglu et al. (2012), path dependence can arise since the knowledge accumulation processes are sectorspecific. Substantial investments previously in a specific field can give increasing returns to future investments in the same field, but when the field reach maturity, the new patent development can stall. Gawel et al. (2016) argues that even though a technology neutral renewable energy support scheme might be cost effective, it is not certain that it arises due to the political economy of the energy sector in different countries. Hence, there might be a large knowledge stock, but it might not have as a big effect as expected. ${ }^{9}$

The main usefulness of a panel approach lies in it allowing for heterogeneity across countries in the sample (Islam 1995). However, if one uses lagged dependent variables in traditional models such as pooled ordinary least squares (OLS) models, or fixed- or random-effects models, there is a substantial risk that the model will yield biased results due to endogeneity issues. Kiviet (1995), therefore, proposes the use of the least squares with dummy variables bias-corrected estimation (LSDVC estimation), which has been found to be quite accurate even when sample size $(N)$ and time $(T)$ are small. The LSDVC estimation is also more efficient than the various instrumental variables (IVs) and generalised method of moments (GMM) estimators that Kiviet tried. One example of a GMM approach was presented by Arellano and Bond (1991), who outlined a two-step method in which lags of explanatory variables in levels were used as instruments. Still, the GMM estimators were originally designed for large $N$ and small $T$. In our paper, $N=13$ and $T=22$, i.e., both are small. For the above reasons, the LSDVC approach is used in the conditional $\beta_{c}$-convergence regression. ${ }^{10}$

\subsection{The sigma-convergence $(\sigma)$ model}

$\sigma$-Convergence is tested based on a dispersion measure widely used in economic growth research. Quah (1993b) suggests a novel methodological approach for testing for $\sigma$-convergence. This approach allows the complex dynamics of evolving cross-country distributions to be discovered. ${ }^{11}$ The measure of $\sigma$-convergence is but a subset of Quah's approach; however, it is a good starting point.

We use the $\sigma$-model to estimate the annual standard deviation of the natural logarithm of renewable energy patent applications per capita. If the dispersion declines

\footnotetext{
${ }^{9}$ On a technical note: if we choose not to apply these interaction terms, $\beta$ represents an average over all sectors. Alternatively, it assumes that there is no heterogeneity across countries. Allowing for heterogeneity-i.e., that $\beta$ depends on country characteristics - is a more general model specification (Brännlund et al. 2015).

10 In the paper the standard Blundell and Bond (1998) estimator with no intercept, is implemented by the Stata routine xtlsdvc.

11 As noted by Boyle and McCarthy (1997, 1999), both Sala-i-Martin (1996) and Quah (1993b) argue that $\beta$-convergence is a necessary but not a sufficient condition for $\sigma$-convergence.
} 
over time, then renewable energy patent applications per capita are converging in a $\sigma$-sense (Barro and Sala-i-Martin 1992). Thus, $\sigma$-convergence can be tested by investigating the cross-sectional standard deviation, $\sigma$ (coefficient of variation), over time and trend. The $\sigma$ can in turn be formulated as follows ${ }^{12}$ :

$$
\sigma_{t}=\sqrt{\left(\frac{1}{N-1}\right) \sum_{i=1}^{N}\left(\ln y_{i t}-\overline{\ln y_{t}}\right)^{2}} .
$$

In Eq. (4), $\ln y_{i t}$ is the renewable energy patent applications per capita for country $i$ at time $t$, and $\overline{\ln y_{t}}$ is the corresponding mean value of the number of patent applications. If $\sigma_{t}$ is trending downward towards zero, or if $\sigma_{t+T}<\sigma_{t}$, then $\sigma$-convergence of per capita patent applications is supported (e.g., Ezcurra 2007; Liddle 2009, 2010).

\subsection{The distributional convergence model}

In line with Liddle $(2009,2010)$, to determine whether the shape of the distribution of renewable energy patent applications has changed and converged over time, the kernel of the density estimates of the distribution can be calculated. The kernel approach is meant to complement the previously addressed $\sigma$-approach, and it offers more information on how the distribution has developed over time.

To some extent, the kernel can reveal distributional dynamics movements such as the formation of twin peaks, polarisation, and stratification. One easy option to detect such movements would be to use histograms, the oldest and best-known nonparametric density function estimator. Histograms would be useful to describe certain data characteristics, but for our purposes, there are drawbacks such as having to make more or less arbitrary decisions about the size of intervals. This makes histograms unsuitable for the estimation of the density function of the distribution under study (Ezcurra 2007).

Instead, the kernel method is used to provide the density of renewable energy patents applications per capita during the period 1990-2012. For this, we use the relative renewable energy patent applications per capita(in Eq. (5) denoted $R y$, to differentiate it from previous estimations), i.e., renewable energy patent applications per capita of each country $i$ at time $t$ divided by the sample average at $t .^{13}$ Specifically, the density of $y$ at point $y_{t}$ is given by:

$$
f\left(R y_{0}\right)=\frac{1}{N h_{t}} \sum_{i=1}^{N} K\left(\frac{R y_{t}-R y_{i t}}{h_{t}}\right),
$$

\footnotetext{
12 For small samples such as the one used in this paper, the denominator $(N-1)$ replaces the usual $n$.

13 This relative measure allows us to avoid some common trends (e.g., overall patenting propensity over time) in patenting activity (Van 2005).
} 
where $f\left(R y_{0}\right)$ is the smoothed parameter used in the graphic representation; $R y_{i t}$ is the density of renewable energy patent applications per capita in country $i$ at time $t ; N$ is the sample size (e.g., the number of countries); $K($.$) is a univariate kernel function;$ and $h$ is the bandwidth, also called the smoothing parameter. For our purposes, the Epanechnikov kernel is used. This kernel is optimal in a mean square error sense, although the loss of efficiency is small for other kernel specifications as well.

\subsection{The $\gamma$-convergence model}

As a complementary measure, the intra-distribution mobility, i.e., the $\gamma$-convergence, is investigated. The use of this complementary measure was proposed by Boyle and McCarthy's (1997), based on the argument that the kernel approach has weaknesses and that there is a lack in generality for the $\sigma$-convergence when testing for $\beta$-convergence. Therefore, they suggest a supplement; an index of rank concordance. The index of rank concordance is referred to as $\gamma$-convergence, and it measures the intra-distributional mobility over time (the position of entities relative to each other). In the context of the current study, intra-distribution mobility shows whether the countries' per capita patent application intensities have remained the same over the years in relation to each other. Constructing the $\gamma$-convergence measure in addition to the other models in this study offers the possibility that, even if the dispersion of renewable energy patent applications per capita declines over time, the individual countries with the highest and lowest intensities could remain the same (Liddle 2009).

To measure the intertemporal distribution of the countries' patenting application output, we examine the change in their ordinal ranking. To this end, we present distributions of patent applications per capita over time. This is done to improve our understanding of changes in the complete distributions over time, which in turn can shed additional light on the intra-distributional dynamics that may not be captured by a single parameter characterising the variance of the cross-section (i.e., $\sigma$-convergence). For a single country, we find the ratio of its renewable energy patent applications per capita to the selected EU country average for each year, i.e., the so-called relative renewable energy patent applications per capita. Normalising a country's renewable energy patent applications against the EU average allows us to discern country-specific movements from global growth or trends in patent applications.

An index was constructed ranging from zero (0) to unity (1). The denominator of the index is the maximum sum of ranks focusing on the concordance between the ranks in year $t$ and year 0 . The closer this index value is to 0 , the greater the extent of mobility has been within the distribution. This index value for each country, as constructed by Boyle and McCarthy (1997), can be calculated as:

$$
\gamma_{i t}=\frac{\text { Variance }\left(\operatorname{AR}(y)_{i t}+\operatorname{AR}(y)_{i 0}\right)}{\text { Variance }\left(2 \operatorname{AR}(y)_{i 0}\right)},
$$

where variance $\operatorname{AR}\left(y_{i t}\right)$ is the actual rank of country $i$ 's patent applications per capita output in year $t$; and $\operatorname{AR}(y)_{i 0}$ is the actual rank of country $i$ 's renewable energy patent applications per capita in the initial year (i.e., $t=0$ ). A change in a countries 
relative position (ranking) will lead a $\gamma_{i t}<1$ after summing all countries $\sum_{n=1}^{N} \gamma_{i t}$, we get a value for how much the countries changed position relatively to each other.

This $\gamma$-convergence index has two distinct advantages: it builds on simplicity and the lack of imposed structure on the data (Liddle 2010). Moreover, it provides a single number traced over time in two dimensions, making it rather easy to interpret compared to some other distribution dynamics plots. ${ }^{14}$ Hence, while $\gamma$-convergence does not capture all the potentially wide-ranging features of a changing renewable energy patent applications distribution, it nonetheless provides an important additional summary indicator to $\sigma$-convergence regarding the nature of the evolving distribution. In our empirical context, a significant movement among the countries across the given time span should not be unexpected. Since the renewable energy field is a rather narrow technological field compared to the aggregate of all patents applied for in a country, a breakthrough could have a large effect on a country's patenting propensity.

\section{Data sources and definitions}

To analyse the convergence pattern over time, a data set containing a balanced panel of 13 of the 15 first EU Member States over the period 1990-2012 was used. ${ }^{15}$ The selection of this period and countries was based on considerations regarding both historical development of the dependent variable and the EU's expansion pattern. The early 1990s also saw a lot of geopolitical changes, such as the reunification of Germany and the expansion of the EU. At the start of the period under study, three countries were not yet members of the EU: Austria, Finland and Sweden only joined in 1995. Several more countries joined in 2004 and in the years that followed. The motivation for not including the post-2004 Member States is because they have (pre2004) been exposed less to the convergence efforts before they entered the Union, and the Eastern European countries did not become a member of the EPO until 2002. For example, the EU's Lisbon Strategy, which put the Knowledge Economy at the centre of economic policy from 2000, called on Member States to make a major effort to invest more in R\&D and other innovation-related activities being performed in the EU.

\footnotetext{
${ }^{14}$ For example, stochastic kernels (e.g., Ezcurra 2007) have been used to generate contour plots of the distribution. However, these three-dimensional figures are not always straightforward to interpret. Alternatively, one can calculate a so-called transition probability matrix, i.e., calculating the probability of a country moving from one category — chosen by the researcher - to another, over a specified timeframe. A downside of this latter approach is that the structure and, hence, the interpretation of such matrices may depend on the discrete categories chosen.

15 The omission of Greece and Luxembourg is due to an insufficient reporting of the needed data. Also, Luxembourg has had minimal public support to renewable energy R\&D.
} 


\subsection{The dependent variable}

In the empirical analysis, the dependent variable $\left(\Delta y_{i t}=\ln \left(y_{i t} / y_{i, t-\tau}\right)\right)$ is the change in renewable energy patent applications per capita (claimed priorities date) by inventor country (descriptive statics on the dependent variable and on renewable energy patenting in Europe is presented in Appendix 2, Tables 5, 6,7). These data were extracted from the statistical database of the Organisation for Economic Co-operation and Development (OECD). ${ }^{16}$

The counts are based on the number of patent applications at the European Patent Office (EPO), and categorised by the inventor's country of origin and counted on priority date. ${ }^{17}$ These types of data have been in used in several other econometric studies as approximations of the impact of technological change and invention (e.g., Budd and Hobbis 1989a, b; Fagerberg 1988; Jungmittag 2004; Jungmittag and Welfens 2002; Jungmittag et al. 1999). EPO patents have an internationally standardised format, which is of great advantage when comparing and using them in empirical analyses (Rübbelke and Weiss 2011).

Even though patents are widely used as a measure of innovation, there are econometric and conceptual criticisms against the use of patent data as a measure of invention output (see e.g., Johnstone et al. 2017; Grafström 2017). The main arguments are that not all new inventions are patented and patents differ greatly in their economic impacts (Pakes and Griliches 1980, 378). Moreover, some patents granted have no economic value or become economically worthless within a relatively short period (Pakes 1985; Schankerman and Pakes 1987). Indeed, the top 10\% of patents have been estimated to capture between 48 and $93 \%$ of total monetary returns (Scherer and Harhoff 2000).

Another reason for why patents are not applied for may be that small firms find the application process difficult; as a result, they may not bother submitting an application (Adams 2005). Instead, firms will employ various types of secrecy to veil their production methods (Cohen et al. 2000; Trajtenberg 2001). Using a set of German patents, for example, Harhoff et al. (2003) showed that the top 25\% of patents accounted for more than $90 \%$ of overall patent economic value.

But, as expressed by Griliches (1990), "In this desert of data, patent statistics loom up as a mirage of wonderful plenitude and objectivity" (p. 287). Even with all potential flaws, patenting records remain a good source for assessing technological change. As Griliches (1998) puts it, "Nothing else even comes close in the quantity

\footnotetext{
16 The data cover the patent application counts in the following renewable energy categories: wind energy, solar thermal energy, solar photovoltaic energy photovoltaic/thermal hybrid solar systems (PVT systems), geothermal energy, marine energy, hydro energy (tidal, stream or dam), hydro energy (conventional), fuel from waste, and bioenergy.

17 The priority date refers to the date when the patent was filed. Only patents filed under the Patent Cooperation Treaty (PCT) were included to approximate innovations in line with OECD recommendations (Hascic et al. 2008). The geographical location of the inventor is considered, and thus not the formal applicant since the applicant can be a company registered in a different country than where the knowledge was produced in the first place (e.g., Fischer et al. 2006).
} 
of available data, accessibility, and the potential industrial, organizational, and technological detail"' (p. 336).

Figure 1 displays the development of total renewable energy patent applications by country. It displays that Germany and Denmark have the most significant total renewable energy patent application output of all the countries in the sample. ${ }^{18}$

Figure 2 displays the number of renewable energy patent applications in the 13 EU Member States by technology. The last 10 years, i.e., 2002-2012 saw a rapid growth in wind and solar energy inventions, while other renewable energy sources seemed to have gained only moderate momentum during the same period.

\subsection{The independent variables}

The control variables that were used when the $\beta$-convergence model was run were in parts gathered from the OECD's Research and Development Statistics database. Several country-specific macroeconomic conditions may be expected to affect the rate and the direction of invention with respect to renewable energy sources. The invention capabilities ${ }^{19}$ of a given country are assumed to depend on three factors: (a) its common invention infrastructure such as R\&D-focused employees and/or R\&D expenditures as well as the stock of previous inventions (e.g., Romer 1990; Grossman and Helpman 1991); (b) its technological and economic specialization, and (c) the quality of the linkages between its common infrastructure and industries that engage in inventive efforts (Jungmittag 2006). The variable definitions and descriptive statistics for each of the variables can be found in Table $1 .{ }^{20}$

Public R\&D spending is commonly considered and used as a variable when analysing countries' innovative capacity (e.g., Dechezleprêtre and Glachant 2013; Furman et al. 2002). In general, public R\&D spending is assumed to add to the innovative process in a country by reinforcing the common innovation infrastructure. For the current study, data on public renewable energy R\&D support were collected from the OECD's Science and technology indicators database. We assume that public R\&D expenditures add to a stock of R\&D-based knowledge in the renewable energy field $\left(K_{i t}\right)$ (Klaassen et al. 2005; Krammer 2009; Söderholm and Klaassen 2007). This knowledge stock is constructed using the so-called perpetual inventory method (Ek and Söderholm 2010). Specifically, the knowledge stock is defined as follows:

$$
K_{i t}=(1-\delta) K_{i(t-1)}+{\mathrm{R} \& \mathrm{D}_{i(t-x)},}
$$

where $\mathrm{R} \& \mathrm{D}_{i t}$ represents the annual public $\mathrm{R} \& \mathrm{D}$ spending on renewable energy, $x$ is the number of years before the R\&D expenditures add to the knowledge stock. The

\footnotetext{
18 Appendix 2, Fig. 6 contains the total number of patents by country.

19 According to Stern et al. (2000), the national innovation capability of a country can be defined as the potential to produce a stream of commercially relevant innovations.

${ }^{20} \mathrm{R} \& \mathrm{D}$ and the number of researchers can, in many cases, be suspected to be related; if there is a strong correlation between them, biased results will be generated. When checking these independent variables, no such high correlation rates were found. A correlation matrix is provided in Appendix 3 (Table C1).
} 


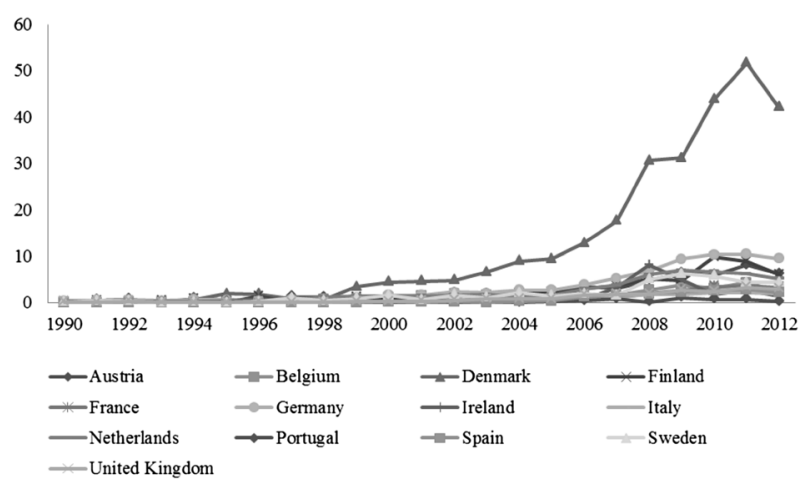

Fig. 1 Renewable energy patent applications per capita by country, 1990-2012. Source: OECD (2014)

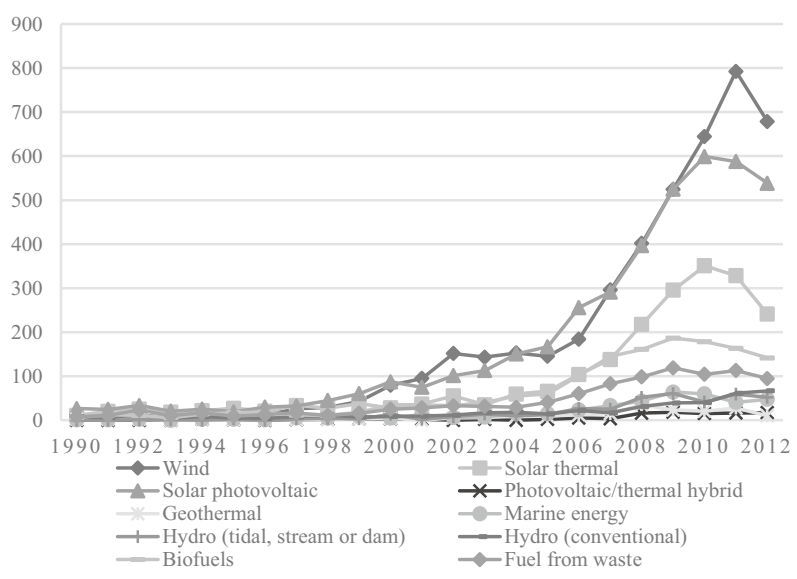

Fig. 2 Renewable energy patent applications in 13 EU Member States by technology, 1990-2012. Source: OECD (2014)

time lag was set to 2 years (Klaassen et al. 2005). Furthermore, the knowledge generated is assumed to depreciate over time; thus, $\delta$ is the annual depreciation rate of the knowledge stock $(0 \leq \delta \leq 1)$ (Hall and Scobie 2006). A depreciation rate of $15 \%$ was used. This is in line with Griliches (1998) and Corradini et al. (2014), but alternative assumptions were also tested (see Appendix 1).

We also need to account for the fact that there was some accumulation of public spending on $R \& D$ for renewable energy sources before the period under study; there was spending in most countries in the first available year in the OECD's stats database, namely 1974. The initial spending level was low in most countries in 1974 . The initial stock $\left(K_{0}\right)$ was calculated as

$$
K_{0}=\frac{\mathrm{R} \& \mathrm{D}_{0}}{g+\delta}
$$




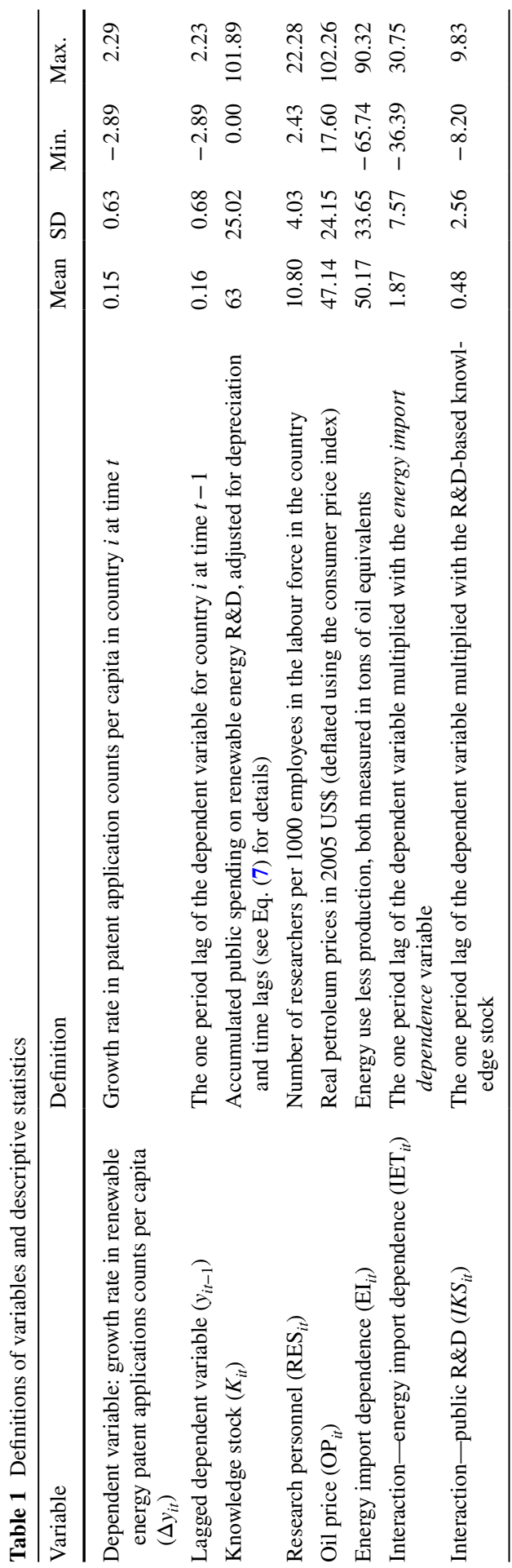


where $R \& D_{0}$ is the amount of public expenditure on renewable energy $R \& D$ in the first year available (1974), and $g$ is the average geometric growth rate for such R\&D spending by country over the first 10 years (e.g., Hall and Scobie 2006; Madsen and Farhadi 2016). ${ }^{21}$

Investment in human capital is necessary for the development of advanced products and new inventions (Romer 1990). The variable Research personnel $\left(\mathrm{RES}_{i t}\right)$ is included in the model to capture the extent of human capital formation. This variable consists of data on the number of researchers per 1000 employees in the respective countries. These data were obtained from the Main Science Technology Indicators published by the OECD.

The return on investing in the development of renewable energy technologies depends on the price of energy substitutes. If the price of oil soars, then the hunt for renewable substitutes is intensified. The Oil price $\left(\mathrm{OP}_{i t}\right)$ variable represents proxies for the price of alternatives to renewable energy sources. For example, Bürer and Wüstenhagen (2009) found that US-based investors were sceptical towards general governmental clean energy support schemes, instead stating that the power of market signals such as high oil prices were the key drivers for their investment. The data for the Oil price series were obtained from the International Energy Agency (IEA 2014b). These data cover real petroleum prices, and were computed by dividing the nominal price in a given month by the ratio of the consumer price index (CPI) in that month to the CPI in some 'base' period. Based on this computation, yearly averages were calculated.

The variable Energy import dependence $\left(\mathrm{EI}_{i t}\right)$ represents energy use minus energy production, both measured in oil equivalents. Energy imports are likely to affect a country's strategic decisions regarding any renewable energy policy. Thus, a country with a high level of energy imports has reason to invest in renewables, since this would reduce its exposure to international fuel price fluctuations and, possibly, supply shock interruptions caused by political instability or future resource constraints (e.g., Neuhoff 2005). The data used to construct the Energy import dependence variable were obtained from the IEA data series on total primary energy supply (IEA 2014c). A negative value indicates that the country is a net exporter.

Two interaction variables are also included. These include the one period lag of the dependent variable multiplied by Energy import dependence and public $R \& D$ knowledge stock, respectively. As was noted above, these interaction variables permit us to test whether the speed of convergence tends to differ across countries with varying characteristics.

\footnotetext{
${ }^{21}$ For some countries, the application of the average geometric growth rate did not matter as minimal R\&D activity was observed in the initial year and, indeed, for some years after that. Formally, we added 1 to each number (to avoid any problems with negative percentages). We then multiplied all the numbers together, and raised their product to the power of 1 , divided by the count of the numbers in the series, and subtracted 1 from the result.
} 


\section{Empirical results}

\subsection{Results from the $\beta$-convergence test}

Table 2 contains the empirical results of Eqs. (2) and (3) for the cross-country panel estimation, i.e., the one testing for conditional $\beta$-convergence. ${ }^{22}$ Model I concern a baseline regression for Eq. (2), while in Model II and III interaction variables are added. Model II contains the variable Interaction-Energy import dependence and Model III contains the variable Interaction-Public $R \& D$.

The results show that $\beta_{c}$ is statistically significant and has a positive sign in all Models I-III. For instance, the $\beta_{c}$ coefficient in Model I has a positive sign (0.371) and is statistically significant, thus suggesting that the per capita renewable energy patent applications counts are diverging.

The coefficient $\beta_{c}$ is large in this study when compared to the corresponding coefficients that usually appear in other convergence research (e.g., addressing changes in GDP per capita). One explanation for this large coefficient is that the patent application production in the renewable energy field does not resemble many other fields in which convergence research has been conducted (e.g., GDP or carbon dioxide). For example, a country that produced 20 patents in 1 year and 24 in the next will have experienced a large growth rate $(20 \%)$. Hence, we cannot expect to see a pattern that resembles a country's general economic growth path where the annual growth rate of the economy is within a 1-3\% range for most developed countries.

The empirical results further reveal that the Knowledge stock was not statistically significant. In the case of the Oil price variable, the results indicate a statistically significant and positive impact (in models I and III), thus suggesting that higher oil prices imply higher growth rates in renewable energy patenting activity.

Moreover, the level of Energy import dependence for a country is found to have a negative and statistically significant impact on the growth rate in the per capita renewable energy patent applications. The result were unexpected, since one could expect that if a countries dependence on something is high then there should be incentives to research alternatives.

The $\beta_{c}$ coefficients in Models II and III also point to diverging renewable energy patenting activities. Models II and III include the respective interaction effects. In both models, the interaction variables were found to be statistically significant and negative. First, the significance of the interaction effect involving energy import dependence implies that the speed of divergence will be lower, the higher the energy import dependence for a country is. A possible explanation is that countries that are heavily import dependent have less incentives to only free-ride on renewable energy development efforts. These countries will engage in some $\mathrm{R} \& \mathrm{D}$, so the rate of divergence does not increase as fast as it would have.

\footnotetext{
${ }^{22}$ Tables 3 and 4 in the Appendix 1 presents the results when assuming the presence of different depreciation rates ( 5 and $10 \%$ ) of the knowledge stock for Model 1. Table 3 shows that the results remained robust, i.e. we find statistically insignificant impacts even when assuming lower or higher depreciation rates. The results for the other variables also remained robust in these different depreciation settings, furthermore 100 and 200 iterations were run with little difference in the coefficient results.
} 
Table 2 Results from the conditional $\beta$-convergence model

\begin{tabular}{llll}
\hline Coefficients & Model I & Model II & Model III \\
\hline$\beta_{c}$ Lagged dependent variable & $0.371^{* * *}(0.06)$ & $0.225^{* * *}(0.03)$ & $0.228^{* * *}(0.02)$ \\
$\beta_{1}$ Knowledge stock & $0.024(0.05)$ & $-0.011(0.02)$ & $0.002(0.01)$ \\
$\beta_{2}$ Research personnel & $-0.063(0.272)$ & $-0.097(0.120)$ & $0.059(0.053)$ \\
$\beta_{3}$ Oil price & $0.248^{*}(0.134)$ & $-0.048(0.05)$ & $0.031^{*}(0.02)$ \\
$\beta_{4}$ Energy import dependence & $-0.0482^{*}(0.04)$ & $-0.063^{* * *}(0.01)$ & $-0.000(0.292)$ \\
$\beta_{5}$ Interaction—energy import dependence & & $-0.236^{* * *}(0.004)$ & \\
$\beta_{6}$ Interaction—knowledge stock & & & $-0.08^{* * *}(0.006)$ \\
Country dummies & Yes & Yes & Yes \\
Year dummies & Yes & Yes & Yes \\
Number of observations & 273 & 273 & 273 \\
Number of countries & 13 & 13 & 13 \\
Number of years & 22 & 22 & 22 \\
Iterations & 200 & 200 & 200 \\
\hline
\end{tabular}

The standard errors are in parentheses

$* * *, * *$ and $*$ denote statistical significance at the 1,5 and $10 \%$ levels, respectively

Second, the statistical significance of the second interaction variable implies that the speed of divergence from the steady-state level will be lower where the R\&D-based knowledge stock for a country is higher (i.e., the patent propensity diverge slower between countries that have invested much in public R\&D).

The divergence result obtained in Models I-III can be due to that agglomeration effects are in play, to some extent, where industries are clustering together because of the presence of positive externalities (knowledge spillovers), but free-riding may also play a part (Head et al. 1995; Rosenthal and Strange 2001). Divergence is consistent with agglomeration effects and free-riding. But, the results obtained shows that the divergence occur slower if a country have high energy imports and a high knowledge stock, under those circumstances it seems less rational to free-ride.

When it comes to divergence, the best-case scenario in respect of renewable energy development is that the knowledge generated is to some extent a public good: some countries can free-ride on other countries' development efforts. However, freeriding might not be sustainable in the long run, because political motives will begin to play a role when it comes to the public continuing to accept that citizens in some EU countries carry the financial burden for others. Furthermore, as was noted previously, spillovers are dependent on the destination country's technological capabilities (e.g., Cohen and Levinthal 1989; Hussler 2004; Mancusi 2008); so, if countries' growth rates are too diverging, the development might be threatened and the divergence increases; the laggard countries will no longer have the capacity to benefit from international knowledge spillovers and the future development of the technological field might be threatened.

Nevertheless, the concept of $\beta$-convergence alone will not help to predict (inconclusively) whether laggard countries will diverge from the most invention-intensive ones. Thus, further investigation of the data is warranted. 


\subsection{Results from the complementary convergence tests}

Figure 3 shows the $\sigma$-convergence results, all normalised to the initial year. A value below one and going towards zero (0) would indicate movement towards convergence during that period, while a number above one (1) indicates divergence. Our data analysis reveals the latter divergent path. The values of the coefficient of variation increased between 1990 and 2012, indicating an increase in the cross-sectional spread of renewable energy patent applications per capita over time. Thus, for our sample of EU Member States, $\sigma$-divergence occurred from 1990 until 2012. To complement the findings of the $\sigma$-measure, and to further determine if the shape of the distribution in per capita renewable energy patent application counts has changed over time, it is useful to investigate the kernel density estimates of the distribution.

Figure 4 illustrates a comparison of the kernel density functions of the first and last year of the data set. Each country's per capita patent application-count levels were normalised to the sample average of the year in the graph. Figure 4 highlights that the initial distribution is different from the one two decades later, although the distribution over the period (1990-2012) is similar, i.e., it exhibits a single-modal pattern. The major mode corresponds with countries that have relative renewable energy patent applications per capita lower than 2 .

Between the years 1990 and 2012, there was a decrease in the mass concentrated around the average in the main mode, as a result of the increased weight by the end of the distributions. In addition, the second mode tended to withdraw from the average during the period considered. Accordingly, the results suggest the presence of a divergence process in the levels of renewable energy patent applications per capita across the sample countries over the period.

Figure 5 shows the $\gamma$-convergence or intra-distribution mobility for the sample, normalised to the initial year. Since 1990 is the starting year, the value is normalised to 1 . The $\gamma$-measure allows us to see whether there was a large change in the distribution for each year in the period. A value of 1 indicates that there was no change in the intra-distributional ranking. The findings show that there was not 1 year without a change in the distribution. For most of the years, the value was above 0.8 .

Figure 5 shows no significant changes in the country ranking of renewable energy patent applications per capita occurring in the early part of the time period, as evidenced by the small change in $\gamma$-distribution in the later part. It is interesting to note, therefore, that the year 2005 saw a larger distribution change from the first year to the next. In the period after 2008 up to 2012, the movement of the $\gamma$-measure gathers momentum again. The year 1995 seems to be the one in which fewest countries changed rank in their per capita production of renewable energy patent applications. The period between 1999 and 2005 revealed more movements in the distribution.

This result should, therefore, be interpreted as a moderate degree of internal change in the distribution, with some tendency towards a larger change of the ranking at the end of the time period. Overall, the lack of intra-distributional mobility indicates divergence, since the countries roughly remain where they are ranked in relation to each other, despite the possibility of a larger variance between them (as the $\sigma$-measure suggests). 


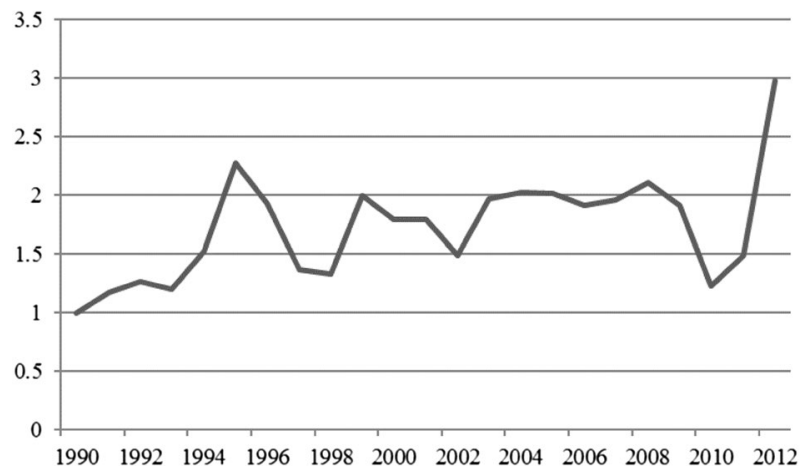

Fig. $3 \sigma$-(Coefficient of variation) divergence in renewable energy patent applications per capita, 19902012

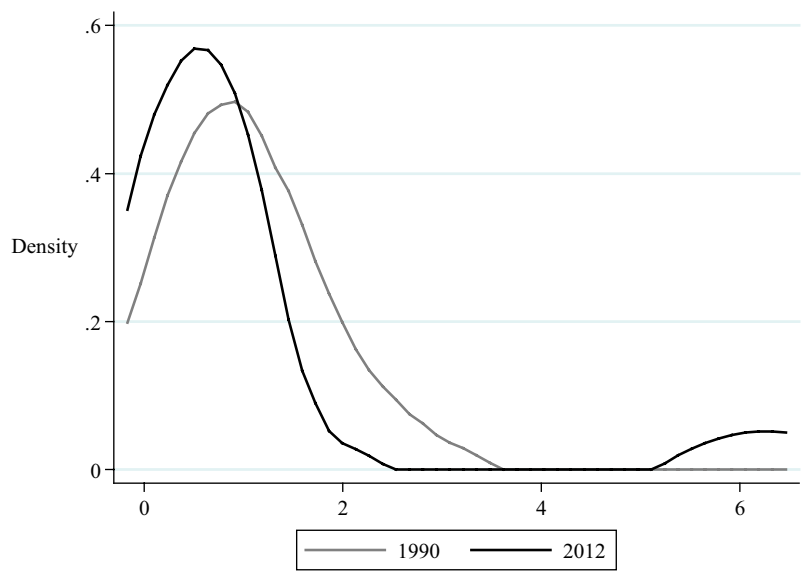

Fig. 4 Kernel density estimates of renewable energy patent applications per capita, 1990 and 2012

Thus, if the countries are on a similar path in terms of invention outcomes, then it is likely that they will change rankings more often. However, if they are on different levels in relation to each other, then there is less room for changes in the rankings-even if there is considerable change in the countries' patenting application outcomes. In the case of patents, a rather large amount of ranking change could be expected during some years. For example, a patent might lead to a significant technological breakthrough, which in turn may lead to several new follow-up patents and hence a rapid increase in the countries ranking.

\section{Concluding remarks and implications}

The objective of this was to investigate the presence of convergence (or divergence) in the per capita patenting activities in the renewable energy field across European countries. The analysis combined both cross-sectional and 


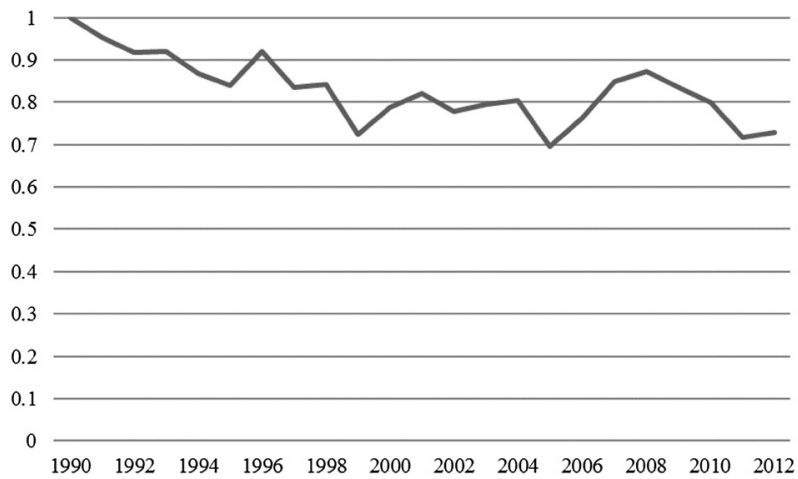

Fig. $5 \gamma$-divergence among the sample countries, 1990-2012

distributional measures to test for convergence, using data on renewable energy patent applications from 13 EU countries over the time period 1990-2012. In both the conditional $\beta$-convergence and $\sigma$-convergence tests, the results indicate the existence of divergence. In the case of $\gamma$-convergence, the movement in the ranking in a country's relative ranking in terms of technological development in the context concerned is not particularly large over the years despite some exceptions, indicating a stable distribution. In other words, countries who were leaders in the beginning of the period studied maintained their position over time.

The divergence begs the following question: what are the implications of this finding, and do the findings constitute a problem? The economic issue is probably less of a concern than any political ones that might arise. From the general perspective of economic growth, who develops technology and where it is developed is less important than the fact that it is being developed in the first place. For technological development and, hence, prosperity, specialization in technologies will probably lead to higher economic growth-which is a policy goal for many governments.

The reported divergence in renewable energy developments may also affect the economic costs of attaining the EU's 2020 and 2030 goals. These diverging pathways raise concerns about the prospects for a transition to a more sustainable energy system for the EU as a whole; there is a risk of a lower level of goal fulfilment regarding renewables in the energy mix. An unfair burden-sharing among its Member States could also undermine the EU's efforts to address the problem of global warming jointly and efficiently due to free-rider issues and sub-optimal investment levels. Given the urgency of addressing the accumulation of greenhouse gases in the atmosphere, for example, there is immense value in developing and expanding the use of low-cost carbon-free technologies relatively quickly.

The renewable energy development invention efforts in various EU countries are heterogeneous, with increase in some countries and modest developments in others. This heterogeneity is in many ways expected: the EU is a collection of different national and regional innovation systems in the renewable energy field development. Thus, some regions seem to be strongly integrated in knowledge transmission, while others continue to be peripheral. One reason why a country is unable to make use of new technology is if it has not built up an absorptive capacity of sufficient magnitude. 
For instance, a low level of own R\&D compromises the potential for making use of knowledge spillovers from abroad, and this can in turn hamper the deployment of new technology. Therefore, some amount of divergence is not a major issue; rather, the problem lies in the possibility that the divergence becomes too great.

As discussed in Sect. 1, divergence in knowledge production may have interesting implications for how we consider productions possibility sets where non-convexity cannot be excluded. The renewable energy case is but one of many technological fields. Nonetheless, it is of some general interest when it comes to the issue of technological development. We know that technological convergence in general plays a key role in general economic convergence. This paper has illustrated that a sub-field of technology in a number of EU Member States is on a divergent path, and this may have implications for general convergence. The results of this study also point to the need for further research on the driving forces behind divergence in technological development efforts. Without such knowledge, it will be hard to identify suitable strategies to ensure an efficient transition to a carbon-free energy system.

Acknowledgements Financial support from the Swedish Research Council Formas and The Ragnar Söderberg Research Foundation is gratefully acknowledged as are the valuable comments and help from Patrik Söderholm, Elisabeth Häggquist and Carol Dahl, as are valuable comments from the reviewers of the paper. Responsibility for any remaining errors, however, resides solely with the author.

Open Access This article is distributed under the terms of the Creative Commons Attribution 4.0 International License (http://creativecommons.org/licenses/by/4.0/), which permits unrestricted use, distribution, and reproduction in any medium, provided you give appropriate credit to the original author(s) and the source, provide a link to the Creative Commons license, and indicate if changes were made.

\section{Appendix 1}

See Tables 3, 4 .

Table 3 Parameter estimates for the conditional convergence model with a 5 and a $15 \%$ depreciation rate to the R\&D-based knowledge stock

\begin{tabular}{lll}
\hline Coefficients & $5 \%$ & $10 \%$ \\
\hline$\beta_{c}$ Lagged dependent variable & $0.371^{* * *}(0.062)$ & $0.371^{* * *}(0.061)$ \\
$\beta_{1}$ Knowledge stock 5 & $0.027(0.06)$ & \\
$\beta_{1}$ Knowledge stock 10 & & $0.024(0.058)$ \\
$\beta_{2}$ Research personnel & $-0.072(0.277)$ & $-0.063(0.272)$ \\
$\beta_{3}$ Oil price & $0.250^{*}(0.134)$ & $0.248^{*}(0.279)$ \\
$\beta_{4}$ Energy imports & $-0.047^{* *}(0.041)$ & $-0.048^{* *}(0.042)$ \\
Country dummies & Yes & Yes \\
Year dummies & Yes & Yes \\
Observations & 273 & 273 \\
Number of countries & 13 & 13 \\
Iterations & 200 & 200 \\
\hline
\end{tabular}

The standard errors are in parentheses

$* * *, * *$ and $*$ denote statistical significance at the 1,5 and $10 \%$ levels, respectively 


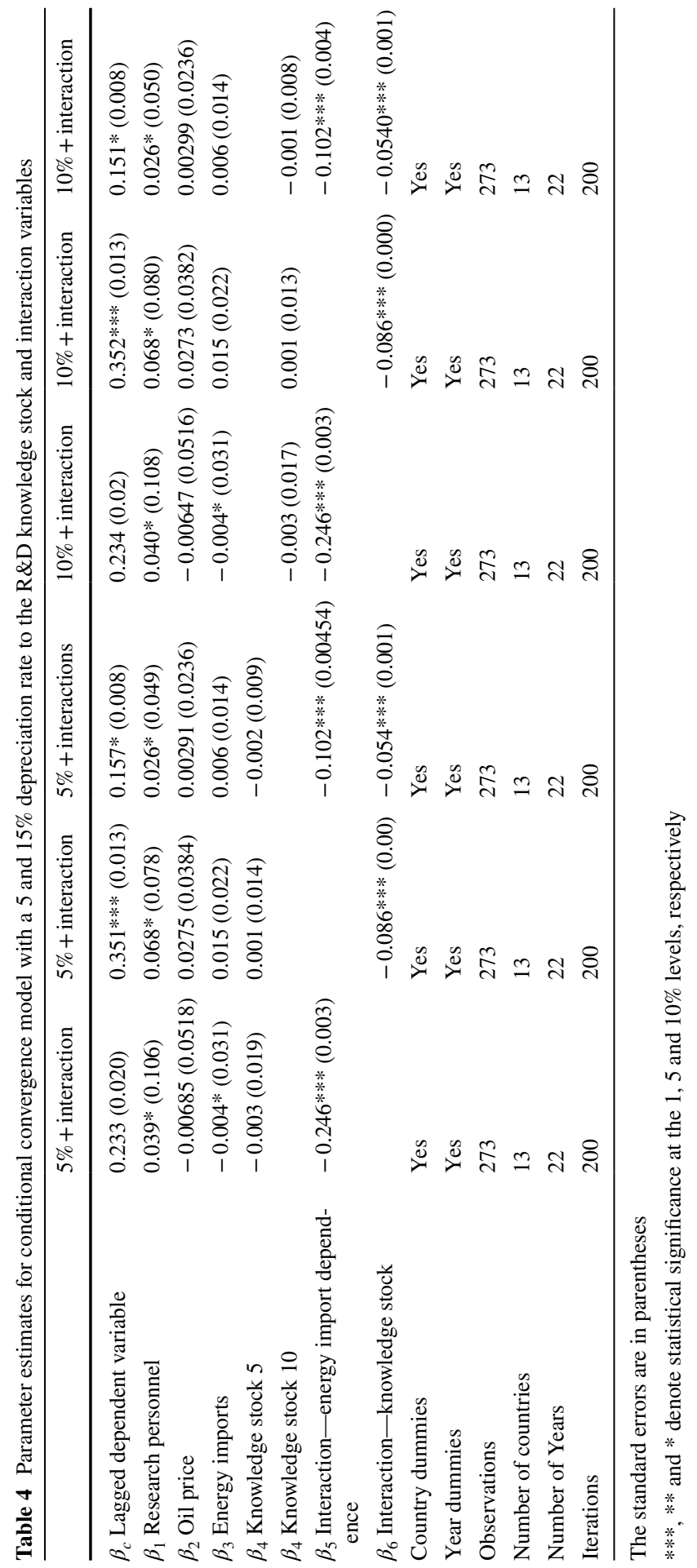




\section{Appendix 2}

See Tables 5, 6, 7 and Fig. 6.

Table 5 Descriptive statistics: dependent variable (not logged) growth (\%) in renewable energy patent applications per capita, by country (note that in some cases the patent count went from 1 to 9 patents in a year, explaining the large changes)

\begin{tabular}{llrrl}
\hline Country & Mean & SD & Min. & Max. \\
\hline Austria & 142 & 101 & -14 & 495 \\
Belgium & 136 & 92 & -47 & 463 \\
Denmark & 168 & 156 & -24 & 597 \\
Finland & 147 & 110 & -24 & 498 \\
France & 121 & 189 & -46 & 185 \\
Germany & 117 & 28 & -58 & 174 \\
Ireland & 160 & 183 & -21 & 888 \\
Italy & 150 & 130 & -37 & 559 \\
Netherlands & 159 & 173 & -5 & 895 \\
Portugal & 160 & 197 & -16 & 934 \\
Spain & 145 & 96 & -36 & 480 \\
Sweden & 156 & 162 & -33 & 798 \\
United Kingdom & 127 & 74 & -49 & 414 \\
Total & 148 & 133 & -5 & 935 \\
\hline
\end{tabular}

Table 6 Descriptive statistics: number of total renewable energy patents applications by country

\begin{tabular}{lcccc}
\hline Country & Mean & SD & Min. & Max. \\
\hline Austria & 17.47 & 16.31 & 1 & 55.79 \\
Belgium & 12.21 & 12.46 & 1 & 38.87 \\
Denmark & 60.28 & 80.06 & 1 & 221.89 \\
Finland & 7.4 & 8.9 & 1 & 24.75 \\
France & 51.89 & 64.9 & 2.33 & 176.73 \\
Germany & 252.26 & 256.67 & 27.5 & 714.59 \\
Ireland & 4.85 & 7.97 & 0.5 & 37.8 \\
Italy & 37.3 & 44.98 & 1 & 125.24 \\
Netherlands & 30.75 & 30.17 & 0.33 & 83.97 \\
Portugal & 3.39 & 3.73 & 1 & 11.08 \\
Spain & 34.53 & 43.65 & 1 & 113.18 \\
Sweden & 13.89 & 14.23 & 1 & 52.78 \\
United Kingdom & 53.92 & 57.41 & 3.83 & 164.27 \\
Total & 44.63 & 101.3 & 0.33 & 714.59 \\
\hline
\end{tabular}


Table 7 Descriptive statistics: number of renewable energy patent applications per million inhabitants, by country

\begin{tabular}{lcclr}
\hline Country & Mean & \multicolumn{1}{c}{ SD } & Min. & Max. \\
\hline Austria & 2.45 & 2.35 & 0.13 & 8.13 \\
Belgium & 1.35 & 1.31 & 0.1 & 4.43 \\
Denmark & 12.2 & 15.98 & 0.19 & 51.62 \\
Finland & 2.43 & 2.79 & 0.19 & 9.82 \\
France & 3.73 & 10.07 & 0.09 & 36.72 \\
Germany & 3.33 & 3.52 & 0.46 & 10.54 \\
Ireland & 1.3 & 1.92 & 0.13 & 8.13 \\
Italy & 0.69 & 0.82 & 0.02 & 2.31 \\
Netherlands & 2.34 & 2.33 & 0.26 & 7.05 \\
Portugal & 0.29 & 0.3 & 0.06 & 1.12 \\
Spain & 0.77 & 1.01 & 0.03 & 2.89 \\
Sweden & 1.86 & 1.94 & 0.11 & 6.34 \\
United Kingdom & 0.99 & 1.07 & 0.09 & 3.4 \\
Total & 2.6 & 6.18 & 0.02 & 51.62 \\
\hline
\end{tabular}

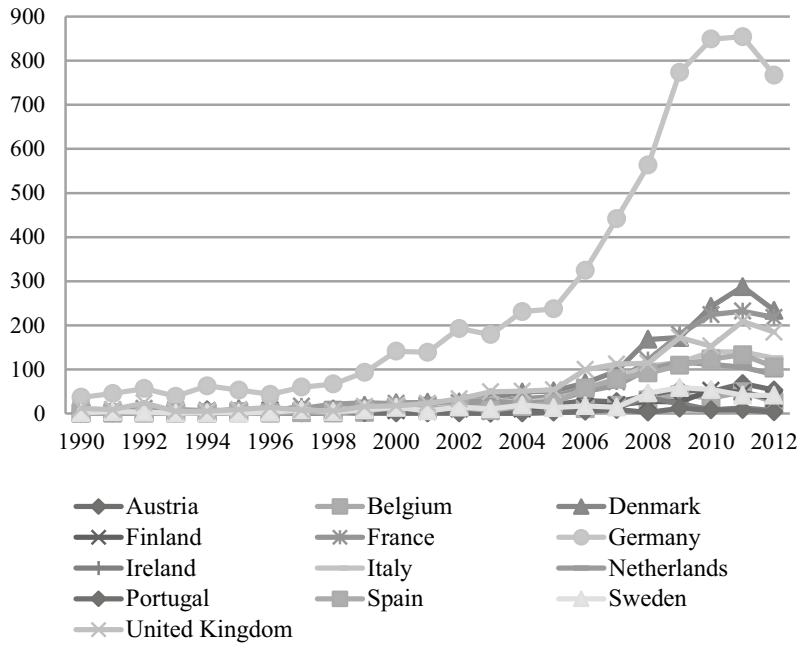

Fig. 6 Renewable energy patent applications per capita by country, 1990-2012. Source: OECD (2014)

\section{Appendix 3}

See Table 8. 


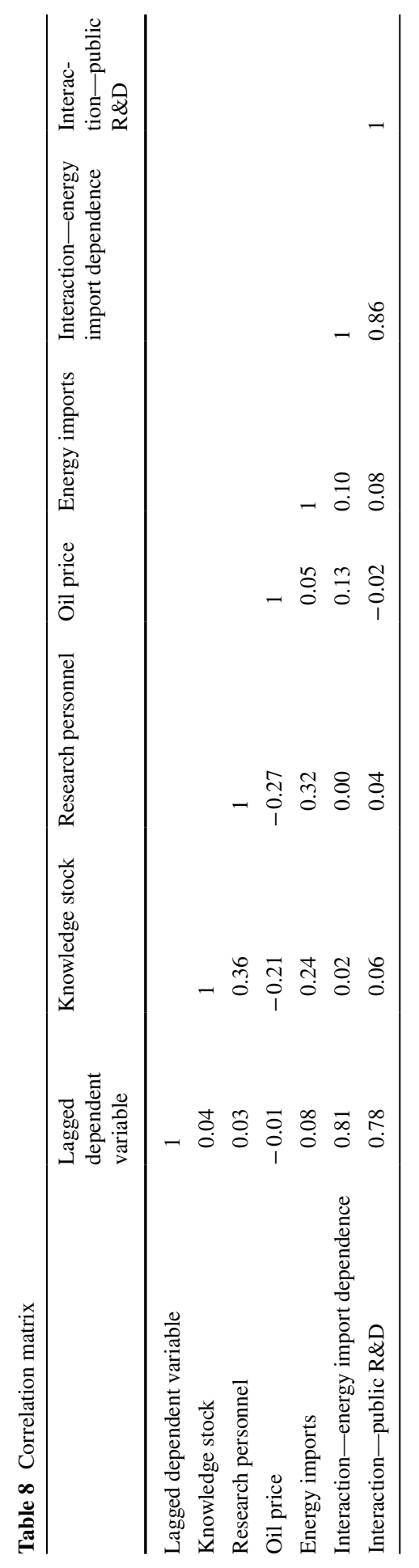




\section{References}

Acemoglu D, Aghion P, Bursztyn L, Hemous D (2012) The environment and directed technical change. Am Econ Rev 102:131-166

Adams SS (2005) Information sources in patents, 1st edn. K. G. Saur Verlag, Munich

Ahamada I, Flachaire E (2010) Non-parametric econometrics, OUP Catalogue. Oxford University Press, Oxford

Aldy JE (2006) Per capita carbon dioxide emissions: convergence or divergence? Environ Resour Econ 33(4):533-555

Antonelli C (2008) Localised technological change: towards the economics of complexity. Routledge, London

Antonelli C, Quatraro F (2010) The effects of biased technological change on total factor productivity: empirical evidence from a sample of OECD countries. J Technol Transf 35(4):361-383

Archibugi D, Filippetti A (2011) Is the economic crisis impairing convergence in innovation performance across Europe? J Common Mark Stud 49(6):1153-1182

Arellano M, Bond S (1991) Some tests of specification for panel data: Monte Carlo evidence and an application to employment equations. Rev Econ Stud 58(2):277-297

Barro RJ (1991a) A cross-country study of growth, saving, and government: national saving and economic performance. University of Chicago Press, Chicago, pp 271-304

Barro RJ (1991b) Economic growth in a cross section of countries. Q J Econ 106(2):407-443

Barro RJ (2015) Convergence and modernization. Econ J 125(June):911-942

Barro RJ, Sala-i-Martin X (1991) Convergence across states and regions. Brookings Papers Econ Activ 1:107-182

Barro RJ, Sala-i-Martin X (1992) Convergence. J Polit Econ 100(2):223-251

Blundell R, Bond S (1998) Initial conditions and moment restrictions in dynamic panel data models. J Econ 87:115-143

Bosetti V, Carraro C, Massetti E, Tavoni M (2008) International energy R\&D spillovers and the economics of greenhouse gas atmospheric stabilization. Energy Econ 30(6):2912-2929

Boyle GE, McCarthy TG (1997) A simple measure of $\beta$-convergence. Oxford Bull Econ Stat 59(2):257-264

Boyle GE, McCarthy TG (1999) Simple measures of convergence in per capita GDP: a note on some further international evidence. Appl Econ Lett 6(6):343-347

Brännlund R, Lundgren T, Söderholm P (2015) Convergence of carbon dioxide performance across Swedish industrial sectors: an environmental index approach. Energy Econ 5:227-235

Brock WA, Taylor MS (2010) The Green Solow Model. J Econ Growth 15(2):127-153

Budd A, Hobbis S (1989a) Co-integration, technology and the long-run production function. Discussion paper, Centre for Economic Forecasting, London Business School

Budd A, Hobbis S (1989b) Output growth and measure of technology. Discussion paper, Centre for Economic Forecasting, London Business School

Bürer MJ, Wüstenhagen R (2009) Which renewable energy policy is a venture capitalist's best friend? Empirical evidence from a survey of international Cleantech investors. Energy Policy 37(12):4997-5006

Cohen WM, Levinthal DA (1989) Innovation and learning: the two faces of R\&D. Econ J 99(397):569-596

Cohen WM, Nelson RR, Walsh JP (2000) Protecting their intellectual assets: appropriability conditions and why US manufacturing firms patent (or not) (No. w7552). National Bureau of Economic Research

Corradini M, Costantini V, Mancinelli M, Mazzanti M (2014) Unveiling the dynamic relation between R\&D and emission abatement: national and sectoral innovation perspectives from the EU. Ecol Econ 102:48-59

Corradini M, Costantini V, Mancinelli S, Mazzanti M (2015) Interacting innovation investments and environmental performances: a dynamic impure public good model. Environ Econ Policy Stud 17(1):109-129

Costantini V, Crespi F (2008a) Environmental regulation and the export dynamics of energy technologies. Ecol Econ 66(2):447-460

Costantini V, Crespi F (2008b) Environmental institutions and the trade of energy technologies in Europe. Int J Glob Environ Issues 8(4):445-460 
Costantini V, Crespi F (2013) Public policies for a sustainable energy sector: regulation, diversity and fostering of innovation. J Evol Econ 23(2):401-429

Costantini V, Crespi F, Martini C, Pennacchio L (2015) Demand-pull and technology-push public support for eco-innovation: the case of the biofuels sector. Res Policy 44(3):577-595

Dechezleprêtre A, Glachant M (2013) Does foreign environmental policy influence domestic innovation? Evidence from the wind industry. Environ Resour Econ 58(3):391-413

Delgado ME, Porter ME, Stern S (2014) Clusters, convergence, and economic performance. Res Policy 43(10):1785-1799

Desdoigts A (1999) Patterns of economic development and the formation of clubs. J Econ Growth 4(3):305-330

Dosi G, Freeman C, Nelson R, Silverberg G, Soete L (1988) Technical change and economic theory. Pinter, London

Durlauf SN, Johnson PA, Temple JR (2005) Growth econometrics. Handb Econ Growth 1:555-677

Ek K, Söderholm P (2010) Technology learning in the presence of public R\&D: the case of European wind power. Ecol Econ 69(12):2356-2362

EPO/European Patent Office (2016) EPO supports new platform on renewable energy innovation. https:// www.epo.org/news-issues/news/2015/20150710.html. Accessed 02 Oct 2016

European Commission (2014) 2030 Framework for climate and energy policies. http://ec.europa.eu/clima /policies/2030/index_en.htm. Accessed 02 Oct 2016

European Commission (2015a) Renewable energy-moving towards a low carbon economy. https:// ec.europa.eu/energy/en/topics/renewable-energy. Accessed 30 Nov 2015

European Commission (2015b) Report from the Commission to the European Parliament, the Council, the European Economic and Social Committee and the Committee of the Regions. COM (2015) 293. European Commission, Brussels

Ezcurra R (2007) Distribution dynamics of energy intensities: a cross-country analysis. Energy Policy 35:5254-5259

Fagerberg J (1988) International competitiveness. Econ J 98(391):355-374

Fagerberg J, Mowery D, Nelson R (eds) (2005) The Oxford handbook of innovation. Oxford University Press, Oxford

Fischer MM, Scherngell T, Jansenberger E (2006) The geography of knowledge spillovers between hightechnology firms in Europe: evidence from a spatial interaction modelling perspective. Geogr Anal 38(3):288-309

Furman JL, Porter ME, Stern S (2002) The determinants of national innovative capacity. Res Policy 31(6):899-933

Gawel E, Lehmann P, Purkus A, Söderholm P, Witte K (2016) The rationales for technology-specific renewable energy support: conceptual arguments and their relevance for Germany (No. 4/2016). UFZ Discussion Papers

Grafström J (2017) International knowledge spillovers in the wind power industry: evidence from the European Union. Economics of Innovation and New Technology, pp 1-20

Griliches Z (1979) Issues in assessing the contribution of research and development to productivity growth. Bell J Econ 10:92-116

Griliches Z (1990) Patent statistics as economic indicators: a survey. J Econ Lit 28(4):1661-1707

Griliches Z (1998) Patent statistics as economic indicators: a survey. In: Griliches Z (ed) R\&D and productivity: the econometric evidence. University of Chicago Press, Chicago, pp 287-343

Grossman G, Helpman E (1991) Innovation and growth in the global economy. MIT Press, Cambridge

Hall J, Scobie G (2006) The role of R\&D in productivity growth: the case of agriculture in New Zealand: 1927 to 2001. New Zealand Treasury, Wellington

Harhoff D, Scherer FM, Vopel K (2003) Citations, family size, opposition and the value of patent rights. Res Policy 32(8):1343-1363

Hascic I, de Vries FP, Johnstone N, Medhi N (2008) Effects of environmental policy on the type of innovation: the case of automotive emissions control technologies. OECD Journal: Economic Studies, Paris

Head K, Ries J, Swenson D (1995) Agglomeration benefits and location choice: evidence from Japanese manufacturing investments in the United States. J Int Econ 38(3):223-247

Hussler C (2004) Culture and knowledge spillovers in Europe: new perspectives for innovation and convergence policies? Econ Innov New Technol 13(6):523-541

IEA/International Energy Agency (2014a) $\mathrm{CO}_{2}$ emissions from fuel combustion-highlights. IEA, Paris Cedex 
IEA/International Energy Agency (2014b) Energy policies of IEA countries-the European Union. IEA, Paris Cedex

IEA/International Energy Agency (2014c) Energy imports, net (\% of energy use). http://www.iea.org/stati stics/statisticssearch. IEA, Paris Cedex

Islam N (1995) Growth empirics: a panel data approach. Q J Econ 110(4):1127-1170

Islam N (2003) What have we learnt from the convergence debate? J Econ Surv 17(3):309-362

Jaffe A (1986) Technological opportunity and spillovers of R\&D: evidence from firms' patents, profits and market value. Am Econ Rev 76:984-1001

Jaunky VC (2013) Divergence in technical efficiency of electric utilities: evidence from the SAPP. Energy Policy 62:419-430

Johnstone N, Managi S, Rodríguez MC, Haščič I, Fujii H, Souchier M (2017) Environmental policy design, innovation and efficiency gains in electricity generation. Energy Econ 63:106-115

Jungmittag A (2004) Innovations, technological specialization and economic growth in the EU. IEEP $1(2-3): 247-273$

Jungmittag A (2006) Innovation dynamics in the EU: convergence or divergence? A cross-country panel data analysis. Empir Econ 31(2):313-331

Jungmittag A, Welfens PJJ (2002) Telecommunications, innovations and the long-term production function: theoretical aspects and a cointegration analysis for West Germany 1960-1990. In: Audretsch D, Welfens PJJ (eds) The new economy and economic growth in Europe and the US. Springer, Berlin, pp 99-127

Jungmittag A, Blind K, Grupp H (1999) Innovation, standardisation and the long-term production function - a cointegration analysis for Germany, 1960-1996. Zeitschrift für Wirtschafts- und Sozialwissenschaften 119:205-222

Keefer P, Knack S (1997) Why don't poor countries catch up? A cross-national test of an institutional explanation. Econ Inq 35(3):590-602

Kerstens K, Managi S (2012) Total factor productivity growth and convergence in the petroleum industry: empirical analysis testing for convexity. Int J Prod Econ 139(1):196-206

Kiviet J (1995) On bias, inconsistency, and efficiency of various estimators in Dynamic Panel Data Models. J Econ 68(1):53-78

Klaassen G, Miketa A, Larsen K, Sundqvist T (2005) The impact of R\&D on innovation for wind energy in Denmark, Germany and the United Kingdom. Ecol Econ 54(2-3):227-240

Krammer S (2009) Drivers of national innovation in transition: evidence from a panel of Eastern European countries. Res Policy 38(5):845-860

Liddle B (2009) Electricity intensity convergence in IEA/OECD countries: aggregate and sectoral analysis. Energy Policy 37(4):1470-1478

Liddle B (2010) Revisiting world energy intensity convergence for regional differences. Appl Energy 87(10):3218-3225

Lucas RE Jr (1988) On the mechanics of economic development. J Monetary Econ 22(1):3-42

Madsen JB, Farhadi M (2016) International technology spillovers and growth over the past 142 years: the role of genetic proximity. Economica 85:329-359

Mancusi ML (2008) International spillovers and absorptive capacity: a cross-country cross-sector analysis based on patents and citations. J Int Econ 76(2):155-165

Martin C, Mulas C, Sanz I (2005) Spatial distribution of R\&D expenditure and patent applications across EU regions and its impact on economic cohesion. Investig Reg 6(5):41-62

Maurseth PB (2001) Convergence, geography and technology. Struct Change Econ Dyn 12(3):247-276

Nelson RR (1987) Understanding technical change as an evolutionary process. North-Holland, Amsterdam

Neuhoff K (2005) Large-scale deployment of renewables for electricity generation. Oxford Rev Econ Policy 21(1):88-110

Nguyen-Van P (2005) Distribution dynamics of $\mathrm{CO}_{2}$ emissions. Environ Resour Econ 32(4):495-508

Nicolli F, Johnstone N, Söderholm P (2012) Resolving failures in recycling markets: the role of technological innovation. Environ Econ Policy Stud 14(3):261-288

OECD.Stat (2014) Data extracted on 20 May 2014 13:23 UTC (GMT) from OECD.Stat

Pakes A (1985) On patents, R\&D, and the stock market rate of return. J Polit Econ 93(2):390-409

Pakes A, Griliches Z (1980) Patents and R\&D at the firm level: a first report. Econ Lett 5(4):377-381

Park WG (1998) A theoretical model of government research and growth. J Econ Behav Organ 34(1):69-85 
Pettersson F, Maddison D, Acar S, Söderholm P (2014) Convergence of carbon dioxide emissions: a review of the literature. Int Rev Environ Recourse Econ 7(2):141-178

Porter ME (2000) Location, competition, and economic development: local clusters in a global economy. Econ Dev Q 14(1):15-34

Quah DT (1993a) Galton's Fallacy and tests of the convergence hypothesis. Scand J Econ 95(4):427-443

Quah DT (1993b) Empirical cross-section dynamics in economic growth. Eur Econ Rev 37(2/3):426-434

Quah DT (1996a) Twin peaks: growth and convergence in models of distribution dynamics. Econ J 106:1045-1055

Quah DT (1996b) Regional convergence clusters across Europe. Eur Econ Rev 40(3):951-958

Quah DT (1997) Empirics for growth and distribution: stratification, polarization, and convergence clubs. J Econ Growth 2:27-59

Rennings K (2000) Redefining innovation-eco-innovation research and the contribution from ecological economics. Ecol Econ 32(2):319-332

Romer P (1986) Increasing returns and long-run growth. J Polit Econ 94(5):1002-1037

Romer P (1990) Endogenous technological change. J Polit Econ 98(5):71-102

Romero-Ávila D (2008) Convergence in carbon dioxide emissions among industrialized countries revisited. Energy Econ 30(5):2265-2282

Rosenthal SS, Strange WC (2001) The determinants of agglomeration. J Urban Econ 50:191-229

Rübbelke D, Weiss P (2011) Environmental regulations, market structure and technological progress in renewable energy technology: a panel data study on wind turbines, Fondazione Eni Enrico Mattei Working Paper Series. Fondazione Eni Enrico Mattei, Milan

Sala-i-Martin XX (1996) The classical approach to convergence analysis. Econ J 106(437):1019-1036

Schankerman M, Pakes A (1987) Estimates of the value of patent rights in European countries during the post-1950 period. National Bureau of Economic Research Working Paper No. 1650 (Also Reprint No. r0861), NBER, Cambridge

Scherer FM, Harhoff D (2000) Technology policy for a world of skew-distributed outcomes. Res Policy 29(4):559-566

Söderholm P, Klaassen G (2007) Wind power in Europe: a simultaneous innovation-diffusion model. Environ Resour Econ 36(2): 163-190

Söderholm P, Ek K, Pettersson M (2007) Wind power development in Sweden: global policies and local obstacles. Renew Sustain Energy Rev 11(3):365-400

Stern S, Porter ME, Furman JL (2000) The determinants of national innovative capacity, NBER Working Paper No. 7876, Cambridge

Strazicich MC, List JA (2003) Are $\mathrm{CO}_{2}$ emission levels converging among industrial countries? Environ Resour Econ 24(3):263-271

Strömberg S (2013) Företag i Energibranschen i Sverige. Vinnova, Stockholm

Tone K, Sahoo BK (2003) Scale, indivisibilities and production function in data envelopment analysis. Int J Prod Econ 84(2):165-192

Trajtenberg M (2001) Innovation in Israel 1968-1997: a comparative analysis using patent data. Res Policy 30(3):363-389

Van PN (2005) Distribution dynamics of $\mathrm{CO}_{2}$ emissions. Environ Resour Econ 32(4):495-508

Žižmond E, Novak M (2007) Controversies of technology convergence within the European Union. Ind Manag Data Syst 107(5):618-635 